\title{
Re-imagining Bleeders: The Medical Leech in the Nineteenth Century Bloodletting Encounter
}

\author{
ROBERT G.W. KIRK and NEIL PEMBERTON*
}

Keywords: Bloodletting; Phlebotomy; Leech; Medical Practice; François-Joseph-Victor Broussais; Leech Craze; Animal Studies

While some historians have noted the absence of animals in medical history, few have made the animal the central object of their historical gaze. Twenty years ago W.F. Bynum urged medical historians to follow historians of science in paying attention to the role of non-human animals in the material practices of medicine. ${ }^{1}$ Yet few have responded to his call. In this paper we again ask the question: what work can the non-human animal achieve for the history of medicine? We do so in the light of the conceptual possibilities opened up by the rapidly emerging field of 'animal studies'. This interdisciplinary and sophisticated body of work has, in various ways, revealed the value of the 'animal' as a tool for exploring the co-constitution of species identity. ${ }^{2}$ We asked ourselves, surely, in our present biomedical world, this must be an area that we as medical historians are best placed to comment on; and what better place to start than the well-known, yet surprisingly little-studied, medical leech?

Jumping in with all our feet, we turned to Donna Haraway for advice and orientation. Haraway, whose work within the history of science and medicine probed the human and animal boundaries long before it was the intellectual fashion to do so, has positioned herself as a leading - though not uncontroversial - voice in the field of animal studies. In 1997, she turned to the OncoMouse, a genetically altered mouse predisposed to develop cancer and designed as a standard laboratory tool, in order to explore the complex interactions that occur across the boundaries of human, animal and machine in the late twentieth-century biomedical sciences. Here, we attempt something similar, but for the leech in early nineteenth-century medical practice.

Following Haraway's figurative cyborgian approach, we will emphasise the always 'leaky distinction... between animal-human (organism) and machine'. 3 During the

(c) Robert G.W. Kirk and Neil Pemberton, 2011.

* Robert G.W. Kirk, Wellcome Research Fellow, and Neil Pemberton, Research Fellow, Centre for the History of Science, Technology and Medicine, The University of Manchester, Simon Building, Manchester M13 9PL, UK.

Emails: robert.g.kirk@manchester. ac.uk and neil.pemberton@manchester.ac.uk

${ }^{1}$ W.F. Bynum, “"C'est un malade”: Animal Models and Concepts of Human Diseases', Journal of the History of Medicine and Allied Sciences, 45 (1990), 397-413.

${ }^{2}$ For further elaboration on this point see Robert G.W. Kirk and Michael Worboys, 'Medicine and Species: One Medicine, One History', in Mark Jackson, The Oxford Handbook of the History of Medicine (Oxford: Oxford University Press, forthcoming).

${ }^{3}$ Donna Haraway, 'A Manifesto for Cyborgs: Science, Technology, and Socialist Feminism in the 1980s', Socialist Review, 15, 2 (1985), 65-107, 152. 


\section{Robert G.W. Kirk and Neil Pemberton}

so-called 'leech craze' of the late eighteenth and early nineteenth centuries the leech was established as a reliable, and in some cases superior, means of venesection ousting the more traditional lancet. This was achieved, we argue, by maintaining the identity of the leech in a conceptual tension between living organism and a mechanical tool. In the bloodletting encounter, medical practitioners' emphasis on the living leech helped the patient to relate to it and experience thereby a non-threatening therapy. At the same time, medical practitioners understood the leech mechanically, in order to sustain its role as a safe, uniform and predictable form of bloodletting. Meanwhile, the nature of the leech itself allowed practices of venesection to reach far beyond the limits of the lancet. The companionable leech made possible the venesection of new bodies, particularly women and children, whilst opening up the interiority of all bodies to medical intervention as never before.

Despite being a comparatively simple creature, the leech, so it seemed to medical practitioners, was capable of considerable behavioural unpredictability that had to be controlled in order to make it a safe and useful medical tool. The success of the leech in the early nineteenth century relied upon it being rendered a predictable and safe medical tool. Accordingly, medical enthusiasts paid unswerving attention to specifying how best to handle and interact with their new companion during the bloodletting encounter. An important point of collaboration was the site at which the leech went to work. Removing a leech that had bitten in the wrong location was an unpleasant and difficult procedure, potentially damaging to leech and patient. Consequently, communication between medical practitioner, leech and patient, a process that operated across the leaky distinctions between animals, human and machine, had to be possible. One technological response to this problem was specially designed leech tubes, which allowed the medical practitioner to communicate precisely the location at which he wished the leech to work (see Figure 1). The aim was to transform a living and breathing creature into a predictable and easy to use medical tool, reconstituting the animal as a reliable, off-the-shelf, standardised, and, eventually, mass-produced medical commodity. Yet, as a living and breathing creature, the leech required more care and consideration than a typical tool.

Traditionally, the leech economy rested on the local knowledge of the rural 'leech gatherer', who used their bare legs as a lure to capture wild leeches. As the 'leech craze' took hold, this practice grew to greater scales, with old horses, cut so they bled, driven through leech ponds so that ever more numbers of leeches could be found to supply the growing trade. Eventually, pioneers recognised a gap in the market and set out to develop systematic methods of leech farming. So-called 'leecheries' consisting of specially built ponds for the express purpose of mass producing leeches were built in urban areas that were a far cry from the natural habitats of the leech. The industrialisation of leech production, however, led to the increasing prominence of diseases amongst leech stocks, which was frequently explained as a consequence of the inadequate quality of their environment and overcrowding. Unsurprisingly, perhaps, the answer to these difficulties was a retreat from the artificial toward mimicking the conditions of nature. Users of mass-produced medicinal leeches became concerned about the differences between domesticated and wild leeches, a debate which reached sophisticated heights of reflexivity as the reliability of knowledge about leeches came to be questioned, due to it being derivative of studies of captive leeches. How to adapt nature so as to serve the needs 


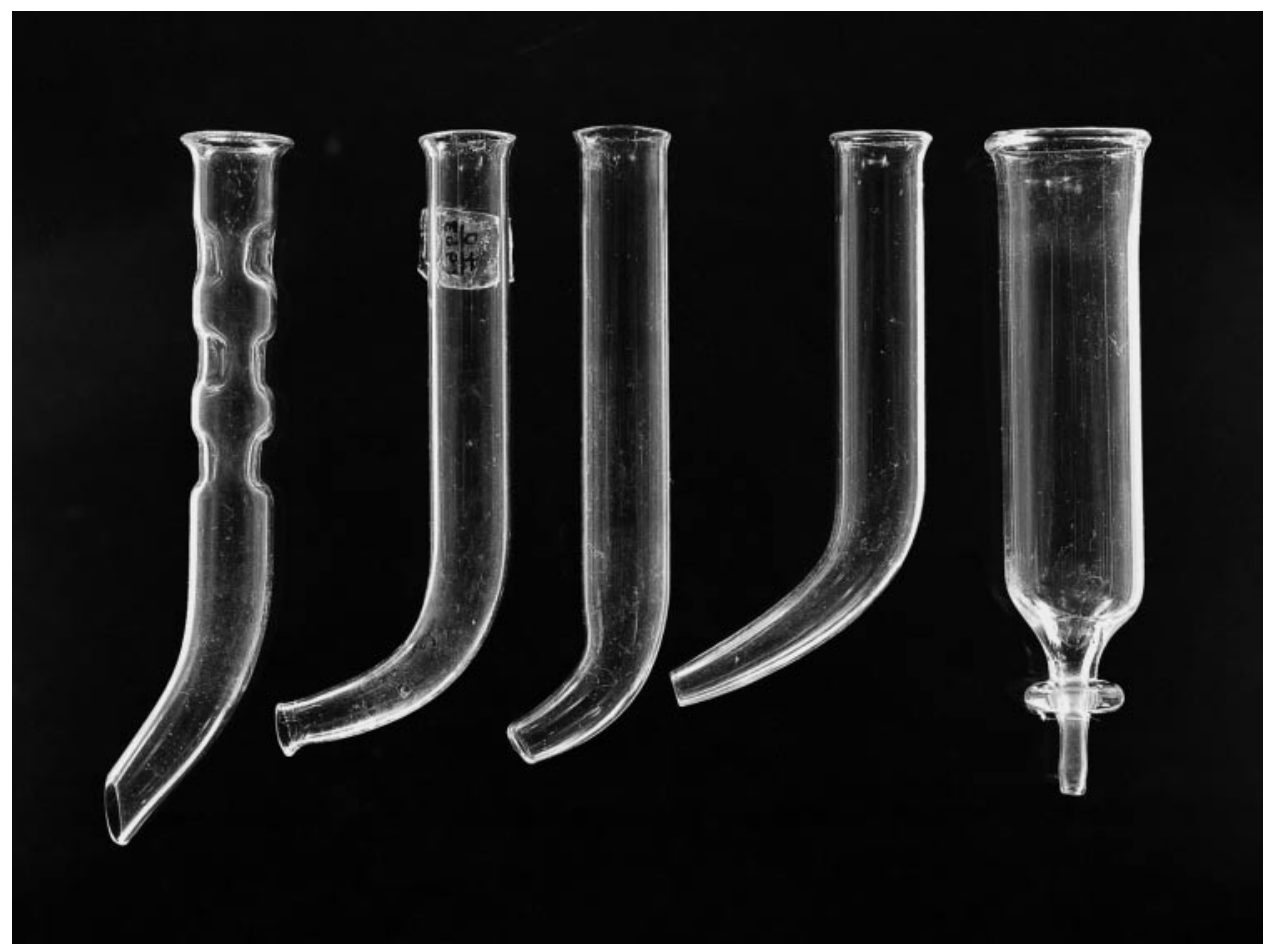

Figure 1: Leech tubes, curved glass. Courtesy: Wellcome Library, London.

of medical commerce without corrupting it thus became an area of keen debate, further blurring boundaries between the natural and artificial.

The complex nature of these debates is reflected in the leecheries of France, widely considered at the time to be the most sophisticated and, moreover, a modern and technical response to the depletion of leeches in the wild. At the same time, the construction of leecheries in urban areas was bringing a certain form of nature into the city. The creation of dense populations of leeches in artificial pools was a process that was not without consequence, attracting the attention of birds, rats and other vermin, which, of course, implied the ever-present threat of disease. In 1864, for example, a disaster was reported in a large French leechery caused by the arrival of a flock of wild geese. Presumably resting en route to warmer climates in what looked like an inviting new pool in the Parisian suburbs; these geese reportedly caused the loss of over 200,000 leeches in one incident (though it is not clear whether the leeches were consumed by the geese or absconded by affixing themselves to the bellies of the birds). The advent of leecheries, which could be said to anticipate twentieth-century factory farming, reveals again the leaky distinction between the categories of the natural and the artificial in the commoditisation of the leech. However, the nature of the leech was equally important in shaping its use in medical practice. 


\section{Robert G.W. Kirk and Neil Pemberton}

In the medical imagination, the utility of the medicinal leech was attributed to its character, particularly its possession of conventionally human values and aptitudes such as sociality and sympathy. The construction of the medicinal leech was textually achieved and maintained by defining its desirable behaviour and manners against those of the horse leech - a creature that was 'said to be 'barbarous' and 'unruly' and 'incapable of civility'. Where the horse leech ate solid food and would eat anything presented to it including its own kind, the medicinal leech refused solid food, appeared sociable to its own species, and possessed an appetite that was comparatively easily satisfied. Docile, passive, and non-aggressive, the medicinal leech was constructed as a courteous creature that was easy to manage. In medical texts the medicinal leech became a worthy human companion, in contrast to the horse leech, which was cast as a savage cannibal and aggressor, feeding on flesh as well as blood.

The contemporary enthusiasm for establishing the ferocious and insatiable appetite of the horse leech against that of the mild and easily contented medicinal leech is remarkable. In 1816, the surgeon James Rawlins Johnson undertook several investigations into the appetite of the horse leech concluding it to be a species of leech with cannibalistic and wild tendencies. ${ }^{4}$ Taming this leech was not an option. The physiology of the horse leech, surgeons like Rawlins Johnson claimed, was faster, more demanding, and in having an insatiable appetite was the opposite of the calm and docile medicinal leech. These persistent references to the calming nature of the leech were articulated elsewhere in discussions concerning the relative value of the lancet as a form of bloodletting. For leech enthusiasts, the lancet constituted a potentially dangerous tool akin to the horse leech. Again, this shows how the categorical distinctions between organic and machine were both disrupted and held in tension. Moreover, the rhetorical appeal to leeches' properties as a living organism enabled a unique set of relationships to emerge between patient, practitioner, and medical tool, which provided the underpinning of a new and influential modern medical cosmology, at the centre of which stood one man.

François-Joseph-Victor Broussais (1772-1838), who made his reputation as a military surgeon in Napoleon's army, became the most iconic medical figure that was associated with the so-called 'mania' for leeches and bloodletting, earning him the sobriquet 'le vampire de la médecine', a reputation that carried the taint of Jacobite terror. Indeed, it is hard not to find historical or historiographical coverage of Broussais that fails to mention his bloody enthusiasm for leeching, as shown in Figure 2 where he prescribes another ninety leeches for his poor bed-bound patient. We do not wish to challenge or undermine this commonplace connection of Broussais with bloodletting, but rather destabilise it by understanding how leeches facilitated and mediated a new kind of bloodletting encounter that was actually underpinned by a relatively non-aggressive therapeutic ideal. For Broussais and his supporters, inside and outside of France, leeching was promoted, not as an aggressive and heroic technique, but rather as a non-invasive and sober means of bloodletting. This perception of the therapeutic value of the leech was tied to the construction of

\footnotetext{
${ }^{4}$ James Rawlins Johnson, A Treatise on the Medicinal Leech: Including its Medical and Natural History, with a Description of its Anatomical
}

Structure; also, Remarks upon the Diseases, Preservation and Management of Leeches (London: Longman, Hurst, Rees, Orme, and Brown, 1816). 


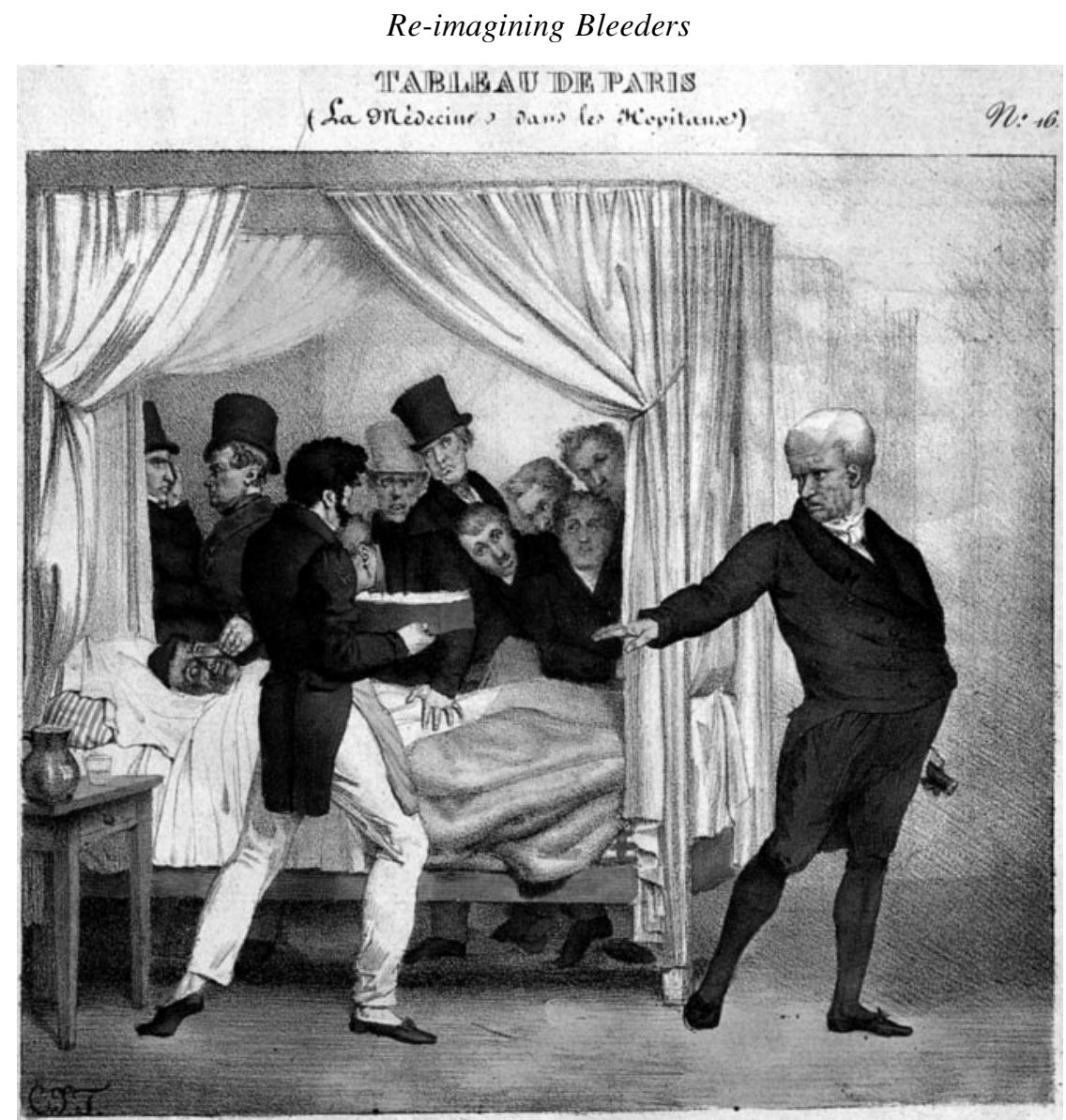

Figure 2: F.J.V. Broussais prescribes another ninety leeches for a sick, bedbound man, while gentlemen crowd around the bed. Paris, $c .1827$. Courtesy: Wellcome Library, London.

the leech as a particularly calm and docile creature, whose compliant nature was vital to overcoming the usually fraught and dangerous practice of bloodletting.

So what were the advantages of the leech? A frequent objection to the lancet made by followers of Broussais was that it 'produced a sudden effect on the action of the heart'. It depleted too much blood too rapidly and risked introducing 'another set of symptoms, more dangerous, perhaps, than those it was intended to obviate - excessive prostration of strength, weak fluttering pulse, irritative fever. . loss of vital energy.' A main advantage of leeches over other methods of venesection was that leeching induced a 'state of relaxation of the nervous energy of the body'. Leech aficionados envisioned a symbiosis between the leech and the human body; as one surgeon wrote, when leeching the 'vascular system adapts itself, in gradual manner, to the loss of a portion of its contents, and the circulation soon becomes equalized, which is not the case after the shock it

${ }^{5}$ For this and following quotations see Rees Price, A Treatise on the Utility of Sangui-suction or Leech

Bleeding: In the Treatment of a great Variety of Diseases (London: Simpkin and Marshall, 1822). 


\section{Robert G.W. Kirk and Neil Pemberton}

received by general bloodletting'. Through the leech's moderate appetite medical practitioners attempted to transform dangerous diseases into milder or more treatable ones, or prevent moderate diseases form turning into dangerous ones. An often fatal limit on venesection had traditionally been the condition of the patient. Prescribing bloodletting indiscriminately in all cases, without any regard to age, constitution, or the force of the disease, was frowned upon even by the most enthusiastic bleeders. The slow and moderate appetite of the leech, however, extended the programme of bloodletting to include 'delicate constitutions' which the violence of the lancet could not safely treat. In addition, the nature of the leech created new frontiers of bleeding: for example, blood now could be drawn from around and within the ears, nose and the mouth, as well as in the rectum and vagina. The opening of the interior of the body often required the physical alteration of the leech, for example the attachment of thread to prevent the loss of the leech within, or the supplementation of the leech with mechanical tools to enable the passage of the creature into locations such as the anus where it was now recommended as a means to treat problematic prostates. In these tender and sensitive areas, where previously bloodletting had been impossible, the small, technologically assisted affable leech could quickly be put to work to provide relief.

The primary aim of this paper has been to lay the case for recognising the significance of placing the non-human animal, in this case the leech, at the forefront of the analysis of the history of medicine. By way of a conclusion, we want to emphasise two points. First, we have stressed that the leech operated as a complex material-semiotic entity, which challenges us to re-imagine our basic assumption of what medicine has been and yet may be. Our encounter with the leech suggests that the animal occupied a central role in the emerging modern medical economy long before 'germ theory' necessitated the mass use of animals in the production of vaccines and harvesting of sera. Our second point is that by examining the leech in this way we can open up new avenues in understanding older narratives within the history of medicine. On this reading, for example, the appetite of Broussais for bloodletting can be seen in a different light. Rather than conflating his political and medical identity, where venesection is read against the bloody years of French terror, a focus on the leech itself reveals a reserved and restrained mode of bloodletting that was a far cry from aggressive and violent therapeutics. In future work, we will explore this key episode in the history of medicine further, locating it as part of a wider historical and cultural moment in which a new sympathetic relation between animal and humans was in the process of being constituted. ${ }^{6}$ We suggest that the invention, production, and civilising of the leech as a medical companion is just one episode of the re-imagining of animal and human relationships within medical modernity. ${ }^{7}$ There are many more yet to explore.

\footnotetext{
${ }^{6}$ An exploration of the constitution of 'human' and 'animal' through categories of moral, economic and humane thinking might best begin with Adam Smith's The Theory of Moral Sentiments (London: A Miller, 1759), within which Smith first referred to the 'invisible hand' and made sympathy the locus of
}

moral behaviour. This point is owed to Professor Roger Cooter, raised at 'The Future of Medical History' conference, The Wellcome Trust Centre for the History of Medicine at UCL, 15-17 July 2010.

${ }^{7}$ Robert G. W. Kirk and Neil Pemberton, Leech (London: Reaktion, forthcoming). 